Tạp chí Khoa học và Công nghệ biển T10 (2010). Số 1. Tr 81 - 96

\title{
MộT SỐ VẤN ĐỀ CƠ BẢN VỀ QUẢN LÝ TỔNG HợP VÙNG BỜ BIỂN Ở VIẸT NAM
}

TRẦN ĐỨC THẠNH

\author{
Viện Tài nguyên và Môi trường biển
}

\begin{abstract}
Tóm tắt: Quản lý tổng hợp vùng bò̀ biển $(Q L T H V B B)$ là mẫu hình mói nhất về quản lý vùng bò̀ biển nhằm tiến tới sụ cân bằng về các mục tiêu môi truờng, kinh tế và xã hội nằm trong phạm vi phù hợp với quá trình tụ nhiên. Nó có chức năng quản lý Nhà nước với thể thức tập trung và được kết nối thống nhất tù̀ Trung uơng đến địa phurong. QLTHVBB đã thu được nhũng thành tựu nhất định, tuy nhiên nhiều nỗ lực quản lý chưa thực sự bền vũng mà lý do quan trọng nhất là thiếu ý chí chính trị và do các nhược điểm tù chính cách thức quản lý hành chính tập trung.
\end{abstract}

Việt Nam có thể chế thuận lợi cho QLTHVBB, đang đượ đặt ra nhu một định huớng tất yếu cho phát triển bền vũng. Hon muời năm qua, một số đề tài nghiên cứu và dự án triển khai, một phần với sự hỗ trợ Quốc tế đã có nhũng đóng góp quan trọng về phổ biến kiến thức, nâng cao nhận thức và tích lũy kinh nghiệm QLTHVBB. Bên cạnh nhũng kết quả bước đầu, sự nghiệp QLTHVBB đang phải đối mặt với những vấn đề cần giải quyết về co sở lý luận, co chế, năng lưc, phương pháp và tài chính bền vũng,... Tù nhận thức đến thực hành hiệu quả là cả một chạng đường dài, QLTHVBB cần đến ý chí chính trị của các cấp chính quyền tù Trung uoong đến địa phuoong và sự áp dụng sáng tạo trong điều kiện thực tiễn Việt Nam.

\section{MỞ ĐẦU}

Vùng bờ biển Việt Nam trải dài trên ba nghìn kilômét, bao gồm các hệ sinh thái tiêu biểu như đảo, cửa sông, đầm phá, vũng, vịnh, rừng ngập mặn, rạn san hô và thảm cỏ biển,... Tài nguyên thiên nhiên và nhân văn vùng bờ biển phong phú và đa dạng cho phép phát triển nhiều lĩnh vực kinh tế quan trọng như giao thông - cảng, nông lâm nghiệp, ngư nghiệp, diêm nghiệp, công nghiệp, khoáng sản, du lịch - dịch vụ. Đây là vùng có nhiều khu bảo tồn thiên nhiên có giá trị và cũng là vùng tập trung dân số có mật độ cao. Hoạt động nhân tác trong điều kiện phát triển nền kinh tế thị trường nhiều thành phần đã gây nhiều ảnh hưởng tiêu cực đến tài nguyên và môi trường vùng bờ biển [18]. Tác động của biến đổi khí hậu gần đây làm gia tăng thiên tai và sự cố môi trường. Trong bối cảnh như vậy, quản lý tổng hợp vùng bờ biển (QLTHVBB) hướng tới phát triển bền vững đã trở thành yêu cầu cấp bách $[6,17]$. Tuy nhiên, để nhân rộng hiệu quả trong thực tiễn, quá trình QLTHVBB ở Việt Nam, từ nhận thức đến thực tiễn, còn phải vượt qua nhiều khó 
khăn và thách thức. Bài viết này trình bày một số vấn đề cơ bản về QLTHVBB ở Việt Nam, một số thuận lợi và những thách thức chủ yếu phải đối mặt giải quyết.

\section{BÀI HỌC TÙ̉ QUẢN LÝ TỔNG HỢP VÙNG BỜ BIỂN Ở NƯớC NGOÀI}

Quản lý vùng bờ biển không chỉ đơn thuần là quản lý Nhà nước mang nặng tính hành chính, mà về bản chất còn có "chức năng sản xuất" nhằm kết hợp các yếu tố đầu vào như lao động, tài nguyên thiên nhiên, vốn và thời gian để tạo ra các sản phẩm mong đợi như nghỉ dưỡng công cộng ở bãi biển, tiện nghi hàng hải, chất lượng nước đảm bảo, các vụ cá hàng năm ổn định, bảo tồn biển, giảm tổn thương do dâng cao mực biển hoặc các tác động tiềm tàng của biến đổi khí hậu,...[22].

Quản lý tổng hợp nhằm phối hợp tất cả các bên có lợi ích về các nhiệm vụ cần thiết để hoạch định và thực thi các hoạt động nhằm bảo vệ, phát triển và sử dụng bền vững các khu vực và các nguồn lực. Nó thừa nhận mối quan hệ tồn tại giữa các hoạt động sử dụng khác nhau và tác động tiềm năng tới môi trường, nhằm vượt qua sự rạn vỡ vốn có khi tiếp cận quản lý theo ngành. Quản lý tổng hợp dựa trên phân tích các khía cạnh phát triển, mâu thuẫn sử dụng, thúc đẩy sự liên kết và hài hoà giữa các hoạt động khác nhau.

Quản lý tổng hợp vùng bờ biển (QLTHVBB) là một chương trình được tạo dựng nhằm quản lý tài nguyên vùng bờ biển, có sự tham gia liên kết của tất cả các ngành kinh tế chịu tác động, các cơ quan Chính phủ và các tổ chức phi Chính phủ [5]. Đó là mẫu hình mới nhất về quản lý các vùng bờ biển, liên kết các hoạt động đối tác, tập hợp các bên có quyền lợi, là một quá trình phối hợp với các hoạt động không trùng lặp. QLTHVBB đánh giá toàn diện, đặt ra các mục tiêu, quy hoạch và quản lý hệ thống vùng bờ biển và tài nguyên, có xét đến các đặc điểm lịch sử, văn hoá và truyền thống, mâu thuẫn lợi ích và sử dụng. Đó là một quá trình tiến hoá liên tục nhằm đạt tới sự phát triển bền vững $[16,23]$.

QLTHVBB là một quá trình động, đa năng và lặp lại. Một chu kỳ QLTHVBB hoàn thiện bao gồm thu thập thông tin, lập kế hoạch, ra quyết định, quản lý, giám sát và đánh giá thực hiện [16]. QLTHVBB dựa vào sự tham gia và phối hợp hành động một cách đồng thuận của tất cả các bên có lợi ích để đạt được các mục tiêu xã hội ở một vùng bờ biển xác định. Về lâu dài, QLTHVBB tiến tới sự cân bằng về các mục tiêu môi trường, kinh tế và xã hội nằm trong điều kiện phù hợp với các quá trình tự nhiên [8]. "Tổng hợp" ở đây mang nghĩa tổng hợp các mục tiêu, tổng hợp nhiều cách thức cần thiết để đạt được mục tiêu, là tổng hợp mọi lĩnh vực chính sách và mọi ngành liên quan, là tổng hợp các phần biển và đất liền của vùng quản lý và tổng hợp về cả không gian, thời gian.

Về bản chất, QLTHVBB có chức năng quản lý Nhà nước với thể thức tập trung và 
được kết nối thống nhất ở ba mức chính quyền: địa phương, tỉnh và Trung ương hài hòa với luật pháp và quy chế của các tổ chức chính quyền [24]. Hiện nay, hầu hết các nền kinh tế vĩ mô của các nước trên Thế giới là kinh tế thị trường phi tập trung, đã bộc lộ rõ những vấn đề cay nghiệt phải đối mặt về tài nguyên và môi trường, dẫn đến khả năng phát triển thiếu bền vững, không chỉ về xã hội, môi trường mà cả về phương diện kinh tế. Vì vậy, QLTHVBB được đặt ra như một tất yếu cho phát triển bền vững, nhưng tiếp cận là cả một con đường dài từ nhận thức, lý luận đến thực tiễn và từ ý tưởng đến thành công.

Vào năm 1972, Hoa Kỳ ban hành sắc lệnh quản lý vùng bờ biển và đó được coi là mốc quan trọng đầu tiên trong lịch sử quản lý tổng hợp vùng bờ biển và Đại dương. Từ đó, lý luận và thực tiễn quản lý vùng bờ biển đã được phổ biến đến các vùng, miền nhờ sự trợ giúp Quốc tế. Đến đầu thế kỷ XXI, Thế giới đã có khoảng 380 địa điểm thực hiện quản lý vùng bờ biển và sau gần bốn thập kỷ thực hành, QLTHVBB đã thu được những thành tựu nhất định phù hợp với mục tiêu phát triển bền vững vùng bờ biển [4]. Một số nước đã đạt được những thành tựu tốt đẹp theo thể thức QLTHVBB ở quy mô Quốc gia, đảm bảo tăng trưởng kinh tế nhưng vẫn bảo vệ được tài nguyên và môi trường. Tuy nhiên có thể nhận thấy, đó là những nước giàu và mật độ dân số không lớn như Thuỵ Điển ở châu Âu [9], hay đất nước diện tích nhỏ như Singapore ở Đông Nam Á [2]. Dẫu sao thì đó cũng là các mô hình có giá trị tham khảo cho các Quốc gia kỳ vọng về phát triển bền vững vùng bờ biển tiếp cận từ quản lý tổng hợp.

Phần lớn các nước Đông Nam Á hưởng ứng tích cực với QLTHVBB, ít nhất là trong thời kỳ nhận được tài trợ cho các dự án thí điểm từ các nước phát triển và các tổ chức Quốc tế. Trong đó, quy mô lớn nhất là các dự án điểm QLTHVBB theo hệ thống của Chương trình đối tác quản lý môi trường các vùng biển Đông Á (PEMSEA) với sự hỗ trợ của Quỹ Môi trường toàn cầu (GEF), Chương trình Phát triển của Liên Hiệp Quốc (UNDP) và Tổ chức hàng Hải Quốc tế (IMO) thực hiện trong thập kỷ đầu tiên của thế kỷ XXI. Đó là các dự án điểm ở Shianoukville (Campuchia), Shihwa (Hàn Quốc), Bali (Indonesia), Klang (Malaysia), Batangas (Philippines), Nampho (Triều Tiên), Hạ Môn (Trung Quốc ), Chonburi (Thái Lan) và Đà Nẵng (Việt Nam) [13].

Tại Malaysia, thể thức tập trung hóa trong quản lý vùng bờ biển định hướng quản lý tổng hợp đã tạo ấn tượng tốt với sự phát triển kinh tế cao, đồng thời vấn đề bảo vệ môi trường được quan tâm đúng mức [10]. Philippines coi trọng và là nước đã thực hiện nhiều nhất các dự án QLTHVBB ở Đông Nam Á, mỗi năm 25 triệu USD ở các nguồn khác nhau được đầu tư cho các dự án quản lý vùng bờ biển. Các dự án nhận được sự hỗ trợ nhiều nhất của chương trình khu vực GEF/UNDP/IMO/PEMSEA đã được triển khai tại Batangas, Bataan, Cavitae, Vịnh Manila và Puerto Galera. Trong đó, dự án QLTHVBB thực hiện trên cơ sở tự chủ - tự quản được coi là thành công hơn cả tại Batangas [3, 13] . 
Tại Hạ Môn (Trung Quốc) với sự hỗ trợ của hoạt động QLTHVBB, từ 1994, hàng năm GDP tăng 9 - 25\% mà không suy giảm chất lượng môi trường $[4,15]$. Bài học thành công của mô hình QLTHVBB ở Hạ Môn trước hết là thắng lợi của ý chí chính trị thông qua sự hỗ trợ về luật pháp, chính sách và tài chính với sự ủng hộ của các cấp chính quyền nhằm tạo một mẫu hình tốt cho Trung Quốc và khu vực. Việc thực thi chính sách và luật pháp nghiêm minh đã tạo nên sự nhất quán và động lực thúc đẩy thực thi chương trình QLTHVBB. Sự đồng thuận của các tổ chức tham gia và của các bên có lợi ích cũng là nhân tố quan trọng đảm bảo cho thành công này. Sự đồng thuận không chỉ là tự nguyện mà còn là tác động chế tài trong khuôn khổ của luật định. Vấn đề thuế và phí môi trường được thực hiện nghiêm chỉnh, tạo nên nguồn tài chính bền vững cho QLTHVBB, đảm bảo cho quá trình này phát triển "tự lực" $[13,15]$. Những kinh nghiệm vốn có về cách thức quản lý trong phát triển nền kinh tế tập trung trước kia có thể cũng góp phần cho sự thành công của mô hình này.

Tuy nhiên, nhiều nỗ lực QLTHVBB chưa thực sự bền vững hoặc chưa thành công, về cơ bản liên quan đến ba lý do chính. Trước hết do thiếu ý chí chính trị hoặc do yếu về cam kết chính trị ở các cấp chính quyền về chính sách, pháp chế và phân bổ nguồn lực để hỗ trợ và duy trì hoạt động của dự án. Thứ hai, do mâu thuẫn giữa các đơn vị tham gia tạo nên sự rạn nứt, thiếu nỗ lực phối hợp làm hạn chế hiệu quả liên kết các bên có lợi ích trong việc ra các quyết định và chính sách. Thứ ba, do sự thay đổi về chính quyền cả ở cấp Quốc gia và địa phương, khi mà chính quyền mới thắng cử không chấp nhận chương trình QLTHVBB đã có [13]. Ngoài ra, QLTHVBB cần quan tâm đến lợi ích và sự tham gia của cộng đồng, nhưng trong nhiều trường hợp, sự tham gia này còn có tính hình thức và phong trào, chưa mang tính bản chất.

QLTHVBB được coi là quản lý đa ngành, đa mục tiêu và đa lợi ích và là chìa khoá của phát triển bền vững. Tuy vậy, ý niệm này hiện chưa hẳn đã được chấp nhận ở mọi hoàn cảnh. Còn có những quan điểm cho rằng QLTHVBB chưa hẳn là cách quản lý tốt nhất và chủ đạo, vì khó có khả năng thành công do chính các nhược điểm từ cách thức quản lý tập trung, khó có khả năng trở thành một quá trình "tự tồn tại”. Không ít nơi vẫn coi trọng vai trò quản lý vùng bờ biển phi tập trung và phát triển các mô hình chủ đạo kiểu “quản lý theo ngành", "quản lý dựa vào cộng đồng". Luật 22/1999 thể hiện rõ ý chí chính trị của Chính phủ Indonesia là phi tập trung quản lý vùng bờ biển và tăng cường vai trò cộng đồng trong quản lý tài nguyên. Quản lý hành chính tập trung được cho là sẽ tạo ra chính sách môi trường áp dụng đồng nhất tại tất cả các vùng của đất nước, thiếu xem xét những vấn đề địa phương và sự đa dạng, phức tạp về kinh tế, văn hóa, xã hội và sẽ tạo ra khuôn phép nặng nề làm hạn chế khả năng suy nghĩ và sáng tạo của chính quyền và cộng đồng địa phương [10]. Thái Lan là nước từ lâu đã quan tâm đến quản lý vùng bờ biển, tuy 
nhiên theo hướng quản lý phi tập trung với phương thức quản lý dựa vào cộng đồng. Từ đó cho thấy cũng không nên tuyệt đối hoá QLTHVBB cho mọi nơi, mọi hoàn cảnh, mà cần có sự phối hợp các cách thức quản lý ở quy mô phù hợp.

\section{THỰC TIẼ̃N QUẢN LÝ TỔNG HợP VÙNG BỜ BIỂN Ở VIẸT NAM}

Tiếp cận QLTHVBB ở Việt Nam đã trải qua hơn 10 năm kể từ đề tài cấp Nhà nước KHCN.06-07 "Nghiên cứu xây dựng phương án quản lý tổng hợp vùng bờ biển Việt Nam góp phần đảm bảo an toàn môi trường và phát triển bền vững" do Viện Tài nguyên và Môi trường biển chủ trì thực hiện trong các năm 1996 - 1999 với hai trọng điểm nghiên cứu là khu vực Đồ Sơn - Cát Bà - Hạ Long và Đà Nẵng [11]. Vào các năm 2000 - 2002, Viện Hải dương học đã tiến hành nhiệm vụ nghiên cứu nhằm xây dựng phương án QLTHVBB Nam Trung bộ với trọng điểm Bình Định theo Nghị định thư hợp tác Việt Nam - Ấn Độ [1].

Tiếp theo, một số dự án triển khai đã được tiến hành với sự hỗ trợ về chuyên gia và tài chính của một số nước và tổ chức Quốc tế. Thành công nhất về mặt lý luận và thực tiễn có lẽ là dự án QLTHVBB tại Đà Nẵng, nằm trong khuôn khổ Chương trình hợp tác của PEMSEA giai đoạn I (2000 - 2006) và giai đoạn II đã được tiếp tục từ năm 2009 [20]. Dự án Việt Nam - Hà Lan về QLTHVBB Việt Nam (VNICZM) giai đoạn 2000 - 2006 được thực hiện ở ba điểm trình diễn Nam Định, Thừa Thiên - Huế và Bà Rịa - Vũng Tàu [7]. Dự án hợp tác về QLTHVBB Hạ Long do IUCN Việt Nam, Bộ Thuỷ sản và UBND tỉnh Quảng Ninh thực hiện trong khuôn khổ hợp tác với Cơ quan Khí quyển và Đại dương Hoa Kỳ (NOAA) trong giai đoạn I (2003 - 2005) và giai đoạn II (2006 - 2008) [12]. Gần đây nhất là dự án quản lý tổng hợp các hoạt động trên đầm phá Tam Giang - Cầu Hai (IMOLA) do FAO tài trợ với sự hỗ trợ của các chuyên gia Italia thực hiện từ năm 2005 và hiện đang tiếp tục gia đoạn II. Chỉ riêng dự án QLTHVBB Quảng Nam (2005 - 2007) là mô hình QLTHVBB cấp tỉnh lần đầu tiên do các nhà khoa học và quản lý Việt Nam xây dựng và thực hiện theo kinh nghiệm của Đà Nẵng [20].

Các hoạt động nói trên đã có những đóng góp quan trọng về phổ biến kiến thức, nâng cao nhận thức và tích luỹ kinh nghiệm QLTHVBB ở Việt Nam [6, 17, 20]. Ở mức độ khác nhau, các dự án triển khai đều chú ý đến thu thập, đánh giá và xây dựng cơ sở dữ liệu và phổ biến thông tin, kể cả việc lập các trang web phục vụ QLTHVBB; quan tâm xây dựng cơ sở vật chất và năng lực quản lý từ việc thành lập và hoạt động của các văn phòng dự án, các nhóm chuyên gia, tư vấn đến mở các lớp tập huấn ngắn hạn, đào tạo chuyên môn GIS, tuyển cử người học tập, thăm quan ở các nước đã có kinh nghiệm,...Sự tham gia của cộng đồng trong hoạt động QLTHVBB đã được chú ý, dù còn mang tính hình thức nhiều hơn là thực chất. Các kế hoạch hành động và các chương trình mang tính chiến lược 
đều được quan tâm soạn thảo. Tuy nhiên, cũng mới chỉ có 4 địa phương cấp tỉnh là Nam Định, Thừa Thiên - Huế, Đà Nẵng và Quảng Nam thông qua được chiến lược QLTHVBB làm định hướng cho hoạt động lâu dài. Các dự án đã ưu tiên triển khai một số hoạt động hỗ trợ quản lý cụ thể: Dự án IMO/GEF/PEMSEA ở Đà Nẵng nhấn mạnh đến ngăn ngừa ô nhiễm; Các dự án VNICZM hợp tác với Hà Lan đã ưu tiên quản lý thiên tai (xói lở, dâng cao mực biển,...) có liên quan đến biến đổi khí hậu và bảo vệ đất ngập nước; Dự án IUCN/ NOAA/MOFI ở Quảng Ninh chú ý đến các khu bảo tồn biển với sự tham gia của cộng đồng, trong giai đoạn II đã xây dựng được một khuôn khổ QLTHVBB Quảng NinhHải Phòng và được chính quyền hai địa phương ký cam kết thực hiện. Dự án IMOLA/FAO đặc biệt quan tâm đến quản lý các hoạt động thuỷ sản trên đầm phá Tam Giang - Cầu Hai,...

Bên cạnh những kết quả tiếp cận khởi đầu đáng ghi nhận, sự nghiệp QLTHVBB ở Việt Nam cũng bộc lộ nhiều tồn tại, khó khăn và phải đương đầu với những thách thức to lớn.

\section{NHŨ̃NG VẤN ĐỀ CƠ BẢN VỀ QLTHVBB Ở VIỆT NAM}

Từ nhận thức và thực tiễn qua các nghiên cứu và hoạt động triển khai, có thể rút ra một số vấn đề cơ bản về QLTHVBB ở nước ta.

\section{1. Định hướng}

Mục tiêu QLTHVBB ở Việt Nam là xây dựng và thực hiện chương trình bao gồm các chu trình quản lý theo định hướng phát triển bền vững trong điều kiện hội nhập và mở rộng hợp tác Quốc tế, trên cơ sở sử dụng hợp lý và bảo vệ tài nguyên - môi trường, bảo tồn thiên nhiên và văn hoá, ngăn ngừa và phòng tránh thiên tai, dung hoà các mâu thuẫn và đảm bảo lợi ích cộng đồng. Quá trình QLTHVBB cần thực hiện các chức năng như dự báo và kế hoạch hóa; điều chỉnh và bổ sung; tổ chức, tập hợp và liên kết; tuyên truyền và giáo dục; giám sát và đánh giá. Một mô hình khung QLTHVBB cần được định hình về mục đích quản lý; các bước trong một chu trình quản lý; chủ thể và phương thức quản lý; phạm vi và đối tượng quản lý; quy mô và cơ chế quản lý; khung hành động và các vấn đề quản lý ưu tiên; tiến trình quản lý [19]. QLTHVBB cần dựa trên các nguyên tắc chủ đạo về tính khả thi và hiệu quả, tính tổng hợp - hài hòa và việc đảm bảo lợi ích cho cộng đồng. QLTHVBB cần dựa trên các tiêu chí như: đảm bảo phát triển bền vững, góp phần thúc đẩy phát triển kinh tế, đảm bảo bảo vệ môi trường, bảo tồn tự nhiên và văn hoá, đảm bảo an ninh quốc phòng; phù hợp và góp phần điều chỉnh tổ chức lãnh thổ, quy hoạch tổng thể địa phương hay vùng. 


\section{Cơ sở pháp lý và ý chí chính trị}

Việt Nam có môi trường tốt cho việc thực thi QLTHVBB. Thể chế được Hiến pháp nước CHXHCN Việt Nam năm 1992 quy định phù hợp với yêu cầu xây dựng cơ chế QLTHVBB mà chủ thể quản lý Nhà nước thông qua các cơ quan chức năng với phương thức quản lý thống nhất và tập trung. Vai trò lãnh đạo đất nước xuyên suốt của Đảng cộng sản, sự ổn định của chế độ chính trị và chính quyền rất quan trọng đối với tính bền vững của quá trình QLTHVBB cần thực hiện trong thời gian rất dài theo các chu trình nối tiếp nhau. Mặc dù còn thiếu các chính sách, luật định cụ thể, nhưng hệ thống văn bản pháp quy hiện có về tài nguyên, môi trường và phát triển bền vững hỗ trợ rất lớn cho hoạt động QLTHVBB $[14,20]$. Tuy nhiên, thực hiện luật pháp thiếu nghiêm minh và chế tài yếu là hạn chế rất lớn cho QLTHVBB.

Ý chí chính trị về phát triển bền vững nói chung và QLTHVBB nói riêng là tích cực. Tuy nhiên ở các cấp địa phương, sự thay đổi chính quyền qua các nhiệm kỳ hay cam kết chính trị yếu từ phía chính quyền có thể dẫn đến thiếu phân bổ nguồn lực và tác động đến tiến trình QLTHVBB. Ngày 9/10/2007, Chính phủ đã ban hành Quyết định số 158/2007/QĐ-TTg phê duyệt Chương trình quản lý tổng hợp dải ven biển vùng Bắc Trung bộ và Duyên hải Trung bộ đến năm 2010 và định hướng đến năm 2020 [21]. Mục tiêu tổng quát của chương trình là tăng cường năng lực quản lý, bảo vệ, sử dụng và khai thác tài nguyên, môi trường, phục vụ phát triển bền vững các tỉnh, thành phố trực thuộc Trung ương trong vùng thông qua áp dụng phương thức QLTHVBB. Mục tiêu cụ thể đến năm 2010 là tạo hành lang pháp lý, hình thành cơ chế, chính sách và tăng cường nguồn lực, cơ sở kỹ thuật để tổ chức thực hiện và triển khai QLTHVBB tại tất cả các tỉnh, thành phố trực thuộc Trung ương trong vùng. Tuy chương trình này ít nhiều còn hạn chế về tính khách quan do chưa có được chỗ dựa nền tảng của chiến lược Quốc gia hay chiến lược vùng về QLTHVBB. Mặt khác, dải ven bờ biển Bắc Trung bộ và Duyên hải Trung bộ chưa hẳn là vùng yêu cầu cấp bách nhất về QLTHVBB xét dưới góc độ tác động nhân sinh. Nhưng quyết định đã thể hiện rõ ý chí chính trị của Chính phủ đối với vấn đề này.

Những kinh nghiệm quản lý trong nền kinh tế tập trung trước đây, có giá trị tham khảo đối với quản lý tập trung trong bảo vệ tài nguyên và môi trường của tiến trình QLTHVBB. Đồng thời, những kinh nghiệm quản lý khi phát triển nền kinh tế thị trường nhiều thành phần định hướng XHCN hiện nay cũng sẽ bổ sung những kinh nghiệm quý báu, tránh những quan liêu dễ có từ cơ chế quản lý hành chính tập trung.

\section{Nhận thức và nhu cầu thông tin}

Nhận thức đúng về vai trò, sự cần thiết và cách thức tiến hành của QLTHVBB cần phải phổ biến và quán triệt trong các cấp quản lý trước khi nâng cao cho cộng đồng. Cần 
tránh cách nghĩ cho rằng QLTHVBB là công việc của các nhà nghiên cứu, còn quản lý vùng bờ và biển là công việc cai quản của các cấp chính quyền. QLTHVBB không phải chỉ tồn tại thông qua dự án, mà các dựa án chỉ là sự khởi đầu mang tính trình diễn và thử nghiệm, để khi hoạt động QLTHVBB đi vào khung ổn định sẽ được chuyển giao cho cơ quan quản lý có chức năng chuyên trách để duy trì thường xuyên.

Nhận thức và hiểu biết về kinh nghiệm thực tiễn QLTHVBB ở Việt Nam vẫn còn hạn chế, thậm chí một số khái niệm còn chưa rõ, có thể dẫn đến hành động thiếu chuẩn xác. Ví dụ, một bộ phận tham gia quan trọng vào quá trình QLTHVBB là "các bên có lợi ich" (stakeholders) thường hiểu lầm là "những người có liên quan". Một số vấn đề về lý luận chưa được làm sáng tỏ, đặc biệt là tính phù hợp giữa cơ cấu tổ chức QLTHVBB với thể chế của nước ta. Sự tiếp thu thiếu lựa chọn lý luận chung và kinh nghiệm của các nước có thể chế xã hội khác nhau có thể dẫn đến các hoạt động QLTHVBB mang tính hình thức và giáo điều. Ví dụ, một chu trình QLTHVBB của PEMSEA gồm sáu bước, nhưng bước đầu tiên "chuẩn bị" khó có thể coi là thời khoảng thực hiện trong một dự án QLTHVBB trong điều kiện Việt Nam. Nhận thức về vai trò quản lý Nhà nước và thể thức quản lý tập trung tuy đã có định hướng đúng, nhưng chưa được thể hiện nổi bật những đặc thù của Việt Nam, có lẽ do còn chịu ảnh hưởng nhiều của tư vấn Quốc tế trong các dự án điểm. Đặc điểm thực tiễn của các địa phương đã được chú ý, nhưng sự lựa chọn ưu tiên trong các hoạt động của dự án còn mang tính cá biệt, làm giảm đi tính chất đa năng của một dự án quản lý tổng hợp.

Để phục vụ cho việc xác định khung hành động, kế hoạch hay chiến lược QLTHVBB, lựa chọn các hoạt động ưu tiên, việc lập hồ sơ môi trường là bước quan trọng đầu tiên, cần đến hệ thống thông tin, tư liệu đầy đủ và toàn diện. Tuy nhiên, những khoảng trống thông tin là vấn đề lớn do tài liệu điều tra cơ bản và quan trắc về tài nguyên, môi trường vùng bờ biển thường thiếu đồng bộ, thiếu độ tin cậy và tính khách quan. Việc bổ sung những tư liệu cần thiết cho các khoảng trống thông tin quan trọng với thời khoảng ngắn trong khuôn khổ một dự án khó có thể đáp ứng.

\section{Xác định phạm vi và đối tượng}

Phạm vi QLTHVBB ở Việt Nam vẫn là một chủ đề cần phải thảo luận và làm rõ. Phạm vi không gian quản lý được xác định theo ranh giới tự nhiên hay hành chính? Sự không phù hợp giữa hai loại ranh giới này nhiều khi gây lúng túng cho lựa chọn không gian quản lý. Cũng không nên quá lệ thuộc vào phạm vi tự nhiên mà điều quan trọng là xác định được không gian nào cần quản lý tổng hợp và mở rộng đến đâu để có tính khả thi và thu hẹp đến đâu khỏi phá vỡ tính hoàn chỉnh của một thực thể tự nhiên ven bờ. Việc chọn ranh giới phía biển, tại độ sâu $30 \mathrm{~m}$ hay $50 \mathrm{~m}$ theo vùng, không quá phức tạp như 
ranh giới phía lục địa. Có lẽ, phạm vi QLTHVBB quy mô từ cấp tỉnh trở lên có sự đồng thuận cao là chọn theo các huyện ven biển, dù một số huyện có phần diện tích rộng thuộc về đồng bằng hay miền núi. Tuy nhiên, tại một số thành phố lớn ven biển, ví dụ như Hải Phòng, các quận sát biển diện tích nhỏ nhưng đều đông dân và hoạt động kinh tế sôi động và nhiều quận sát kề phía sau vẫn mang đậm bản chất ven bờ biển về cả tự nhiên và kinh tế - xã hội, cũng cần được đưa vào phạm vi không gian QLTHVBB.

Hiện đang có xu thế lấy quy mô QLTHVBB cấp tỉnh làm quy mô cơ bản. Có lẽ đó là một lựa chọn đúng đắn với điều kiện hầu hết các quận, huyện sát biển của 28 tỉnh, thành phố trực thuộc Trung ương ven biển có quy mô diện tích và dân số vừa phải. Tuy nhiên, ở không ít trường hợp, mô hình này không phải không có những bất cập. Nhiều tỉnh ven biển ở Bắc bộ và Nam bộ chung nhau các cửa sông lớn và thẳng nên phần nửa cửa sông thuộc tỉnh này có nội dung, tiến độ QLTHVBB khác với phần nửa còn lại của tỉnh kia, hoặc thậm chí phần nửa này được QLTHVBB còn phần nửa kia thì không. Tình trạng tương tự cũng có thể xảy ra giữa các tỉnh chung nhau một thực thể tự nhiên như một bán đảo (ví dụ, Đà Nẵng và Thừa Thiên - Huế có chung bán đảo Hải Vân); hay một vịnh biển (ví dụ, Quảng Ninh và Hải Phòng đều có không gian bờ của vịnh Hạ Long). Vì vậy, QLTHVBB theo đơn vị hành chính cấp tỉnh có lẽ không nên là mô hình duy nhất, mà có thể bổ sung những mô hình theo đơn vị hành chính cấp dưới tỉnh. Đặc biệt, cần có cả mô hình QLTHVBB theo các thực thể tự nhiên như một vịnh biển, một vùng cửa sông lớn hay một hải đảo để khắc phục những hạn chế mô hình đơn vị hành chính cấp tỉnh và thể hiện tính năng động, sáng tạo và tính đa dạng, miễn là tuân thủ đúng các nguyên tắc chung và đáp ứng mục tiêu của QLTHVBB. Mặt khác, ở Việt Nam đang hình thành các vùng phát triển kinh tế - xã hội ven biển như: ven biển Bắc bộ, ven biển Bắc Trung bộ, ven biển Nam Trung bộ và ven biển Nam bộ. Ngày 10 /7/2008, Thủ tướng Chính phủ đã ra Quyết định số 865/QĐ-TTg về việc phê duyệt quy hoạch xây dựng vùng Duyên hải Bắc bộ đến năm 2025 và tầm nhìn đến năm 2050. Tính thống nhất và hoàn chỉnh của một vùng ven bờ biển về điều kiện tự nhiên và kinh tế - xã hội đặt ra những vấn đề chung về QLTHVBB của một mô hình cấp vùng. Mô hình cấp vùng có lẽ cần được coi là một đặc thù riêng của Việt Nam tạo nên một hệ thống QLTHVBB cấp Quốc gia, cấp vùng và cấp địa phương (tỉnh, thành phố trực thuộc Trung ương và các đơn vị hành chính cấp dưới tỉnh). Tuy nhiên, về cơ cấu tổ chức, khung hành động, chiến lược và kế hoạch hành động giữa các cấp vừa cần có sự thống nhất, vừa cần có sự phân định rạch ròi về chức năng và nhiệm vụ. Malaysia cũng có mô hình QLTHVBB cấp bang, mặc dù các bang không có quy mô lớn bằng vùng của Việt Nam.

Đối tượng QLTHVBB ở Việt Nam cũng là vấn đề cần được làm rõ thêm. Tài nguyên và môi trường chắc chắn là đối tượng chủ chốt của QLTHVBB và là trách nhiệm 
quản lý và bảo vệ của Nhà nước, vì các công ty đầu tư, các ngành và các tổ chức, cá nhân trong trong nền kinh tế thị trường vì lợi ích của riêng mình khó có thể có những quan tâm thích đáng tới vấn đề này. Thế nhưng các hoạt động kinh tế nằm trong phạm vi không gian quản lý của hoạt động QLTHVBB có thuộc về đối tượng quản lý của quá trình này? Chương trình QLTHVBB không làm thay công việc quản lý của các ban, ngành chức năng khác, cũng như không đóng vai trò quản lý bao trùm lên các hoạt động của các chương trình kinh tế - xã hội khác. Nhưng chắc chắn, QLTHVBB cần quan tâm đến những hoạt động kinh tế - xã hội gây tác động đến tài nguyên và môi trường hoặc chịu tác động của quá trình QLTHVBB, kể cả mặt thúc đẩy phát triển hoặc hạn chế phát triển các hoạt động đó, thông qua vai trò tham gia và trách nhiệm của các bên có lợi ích, đặc biệt là bên có lợi ích kinh tế. Vấn đề này, rõ ràng cần tiếp tục được bổ sung và làm rõ qua các trải nghiệm thực tế với các hoàn cảnh cụ thể.

\section{Tăng cường tổ chức và năng lực}

Hiện nay, đầu mối tổ chức QLTHVBB cấp Quốc gia theo chức năng thuộc về Tổng cục Biển và Hải đảo Việt Nam, trực thuộc Bộ Tài nguyên và Môi trường. Đây là điểm mới về mặt thể chế, nhưng giai đoạn đầu sẽ không thuận lợi vì còn thiếu cơ chế, chính sách liên ngành để Tổng cục Biển và Hải đảo Việt Nam phối hợp với các bộ và các tỉnh, thành phố trực thuộc Trung ương thực thi QLTHVBB. Ở Trung Quốc, Tổng Cục Đại dương Quốc gia đảm trách nhiệm vụ đầu mối này và cũng thuộc một Bộ đa ngành trực thuộc Quốc Vụ viện.

Một trong những điều kiện quyết định sự thành công của quá trình QLTHVBB là tổ chức bộ máy hoạt động, xây dựng các nhóm chuyên gia, nhóm tư vấn và đào tạo nguồn nhân lực. Sau nhiều năm tiếp cận, chúng ta gần như chưa có các chuyên gia về QLTHVBB theo đúng nghĩa của từ này. Một trong những khó khăn là QLTHVBB cần tiếp cận về mặt phương pháp luận của khoa học xã hội, đồng thời lại cần sự hiểu biết sâu sắc về các đối tượng quản lý thuộc về lĩnh vực khoa học tự nhiên. Các chuyên gia tư vấn, các nhà nhà khoa học tham gia dự án có thể từ các viện nghiên cứu, các trường đại học, thậm chí từ các tổ chức Quốc tế. Tuy nhiên, lực lượng điều hành quản lý trực tiếp tại các văn phòng dự án phải là các cán bộ nguồn địa phương. Hiện tại, lực lượng này còn mỏng về số lượng, hạn chế về lý luận quản lý tổng hợp, chưa đủ sức tiếp thu có lựa chọn kinh nghiệm từ nước ngoài và đề xuất, điều hành các hoạt động trong phạm vi trách nhiệm của mình. Đó là một thực tế khó khăn cần được cải thiện thông qua việc đào tạo chuẩn bị nhân lực trước mắt và lâu dài mà Nhà nước cần có sự quan tâm về tầm chiến lược vĩ mô.

\section{Xác định nguồn tài chính bền vững}

Không chỉ ở Việt Nam, nhiều hoạt động QLTHVBB ở nước ngoài chưa trở thành 
quá trình tự lực do thiếu nguồn tài chính đầu tư ổn định và rơi vào tình trạng hết tài trợ là ngừng dự án. Vì vậy, việc xác định nguồn tài chính đầu tư bền vững là hết sức quan trọng nhằm đảm bảo cho sự tồn tại lâu dài và hoạt động hiệu quả của một chương trình QLTHVBB. Các nguồn tiềm năng, trước hết phải là từ ngân sách Nhà nước, giúp cho duy trì bộ máy, đảm bảo các hoạt động định kỳ, tương tự như khoán chi định mức cho các đơn vị sự nghiệp nhà nước hiện nay. Thuế tài nguyên - môi trường và phí môi trường cần trở thành nguồn hỗ trợ chính và thường xuyên cho QLTHVBB. Kinh phí từ việc thực hiện các đề tài, dự án bảo vệ tài nguyên và môi trường trong phạm vi vùng quản lý do chỉ định hay tuyển chọn theo các quy định hiện hành cũng là nguồn bổ sung quan trọng. Ngoài ra, còn có các nguồn tài trợ Quốc tế và trong nước, đóng góp tự nguyện của các tổ chức và cá nhân,...

Ngoài tạo nguồn bền vững, cũng cần xác định cơ chế sử dụng tài chính đầu tư phù hợp với các hoạt động của quá trình QLTHVBB nhằm ổn định các hoạt động như vận hành bộ máy quản lý, duy trì hệ thống thông tin, quan trắc và đánh giá môi trường, tư vấn và kiến nghị điều chỉnh quy hoạch, thực thi các dự án đầu tư bảo vệ tài nguyên và môi trường,... Cũng cần phải có cơ chế hình thành và hoạt động các quỹ QLTHVBB làm nền tảng cho hoạt động các dự án quan trắc, nghiên cứu và ứng dụng triển khai các vấn đề nằm trong khuôn khổ QLTHVBB. Đây chính là điểm khác biệt với sử dụng tài chính cho các hoạt động quản lý hành chính đơn thuần. Đầu tư tài chính bền vững phải gắn với quá trình tồn tại "tự lực" của chương trình QLTHVBB. Nếu nguồn tài chính đầu tư kiểu bao cấp theo cơ chế tập trung sẽ phát sinh "quan liêu", không thể đảm bảo cho quá trình QLTHVBB tự lực lâu dài. Nhưng nếu không có sự hỗ trợ căn bản từ ngân sách, sẽ thiếu nền tảng, thiếu ổn định. Vì vậy, cơ chế quản lý tài chính ở đây theo phương thức của các đơn vị sự nghiệp Nhà nước có thu, với mô hình bán tự chủ để phát huy năng động, sáng tạo của đội ngũ quản lý, chuyên gia và nhân viên trong hệ thống tổ chức quản lý. Cũng nên tham khảo mô hình quản lý tài chính của các tổ chức khoa học theo Nghị định 115 của Chính phủ về tự chủ, tự chịu trách nhiệm trong hoạt động khoa học cho các tổ chức QLTHVBB.

\section{Mâu thuẫn lọii ích, sự tham gia của cộng đồng và các bên có lọii ích}

Trong các dự án QLTHVBB ở Việt Nam, mâu thuẫn lợi ích là vấn đề tế nhị và thường bị né tránh. Không thể phát triển đa ngành, đa lợi ích, đa mục tiêu nếu không đối mặt để giải quyết vấn đề mâu thuẫn lợi ích. Các mâu thuẫn lợi ích ở vùng bờ biển thường xuất hiện do tranh chấp không gian, tranh chấp tài nguyên và tác động tiêu cực đến môi trường làm ảnh hưởng đến nhóm lợi ích khác. Các hình thức mâu thuẫn có thể xuất hiện giữa hai hay nhiều lĩnh vực (du lịch - nghề cá - giao thông) theo một chiều hoặc đa chiều, có thể trong nội bộ một ngành (nuôi trồng và đánh bắt thuỷ sản), giữa cá nhân và cộng 
đồng, giữa bảo tồn tự nhiên và phát triển kinh tế. Mâu thuẫn có thể xuất hiện khi có quyết định giá trị sử dụng trực tiếp hay gián tiếp hoặc quyết định các giá trị phi sử dụng của cùng một loại tài nguyên. Tuy nhiên, đáng ngại hơn cả chính là mâu thuẫn giữa các đơn vị tham gia QLTHVBB có thể xuất hiện dẫn đến sự rạn nứt của chương trình.

Không thể thực hiện thành công QLTHVBB hướng tới phát triển bền vững khi lợi ích cộng đồng không được đảm bảo. Đó là những lợi ích không chỉ về vật chất, mà còn về sức khoẻ và văn hoá - tinh thần. Mô hình QLTHVBB phải hướng tới lợi ích cộng đồng và góp phần xoá giảm đói nghèo. QLTHVBB phải chú ý đến các vấn đề bảo vệ và duy trì tài nguyên truyền thống, cải thiện sinh kế, tạo việc làm mới, giữ gìn chất lượng môi trường sống, tôn trọng tâm linh và giữ gìn các di sản văn hoá. Muốn đảm bảo được lợi ích chính đáng và sự đồng thuận của cộng đồng thì quá trình QLTHVBB cần phải có sự tham gia của họ. QLTHVBB ở Việt Nam cần tránh hai xu hướng thái quá. Xu hướng thứ nhất điều hành quản lý (management) vùng bờ biển giống như cai quản (governance), tuyệt đối hoá hệ thống luật định và các biện pháp chế tài mà coi nhẹ giáo dục, tuyên truyền, nâng cao ý thức tham gia "tự giác" của cộng đồng và các bên có lợi ích. Xu hướng thứ hai là QLTHVBB kiểu "phong trào" khi đề cập đến sự tham gia của cộng đồng, nhiều khi rơi vào tình trạng quản lý phi tập trung như "quản lý dựa vào cộng đồng" mà coi nhẹ vai trò quản lý Nhà nước. Thực ra, quản lý dựa vào cộng đồng thường do các tổ phi chính phủ đứng ra đảm trách có một vai trò nhất định ở những quy mô và thời điểm thích hợp, có thể có những đóng góp nhất định nhưng không thể thay thế vai trò quản lý tập trung của Nhà nước trong tiến trình QLTHVBB.

Sự tham gia của các bên có lợi ích vào hoạt động QLTHVBB ở nước ta chưa được xác định rõ ràng. Cộng đồng là một bộ phận đông đảo có lợi ích rộng về cả vật chất lẫn tinh thần liên quan đến chương trình QLTHVBB và sự tham gia của họ luôn được đề cao. Tuy nhiên, còn các bên có lợi ích khác, đặc biệt là các bên có lợi ích về kinh tế, đại diện là các công ty, các doanh nghiệp Nhà nước hoặc tư nhân, các tập đoàn kinh tế và các dự án đầu tư phát triển là các bên tham gia quan trọng cần được xác định rõ cơ chế tham gia, trách nhiệm chia sẻ và phải được coi là một nguồn lực đóng góp quan trọng, tham vấn ý kiến, chấp hành các chế tài và cả quyền được hưởng các lợi ích do QLTHVBB mang lại.

\section{KẾT LUẬN}

QLTHVBB là một định hướng đúng đắn có tính khả thi để hướng tới phát triển bền vững. Do hoàn cảnh kinh tế - xã hội, có những sự khác biệt nhất định trong việc áp dụng mô hình QLTHVBB ở các nước khác nhau, đặc biệt ở các nước phát triển và đang phát triển. Mặc dù đã có những mô hình thành công ở một số nước hoặc một số nơi, nhưng 
nhiều hoạt động QLTHVBB chưa đạt được hiệu quả cao và chưa trở thành một quá trình "tự lực".

Những bài học QLTHVBB ở các nước rất có ý nghĩa đối với việc lựa chọn mô hình QLTHVBB cho Việt Nam - một nước mà thể chế xã hội có rất nhiều thuận lợi cho phương thức quản lý này. Bên cạnh những kết quả bước đầu, sự nghiệp QLTHVBB đang phải đối mặt với những vấn đề cần giải quyết về cơ sở lý luận, cơ chế, năng lực và phương pháp,... Ngoài mô hình cấp tỉnh, cần xây dựng một số mô hình khác, trong đó có mô hình cấp vùng hay mô hình theo địa hệ tự nhiên. Để đảm bảo QLTHVBB trở thành quá trình tự lực, cần phải xác định được cơ chế đầu tư tài chính bền vững và không né tránh giải quyết mâu thuẫn. QLTHVBB phải hướng tới lợi ích, sự tham gia cộng đồng và các bên có lợi ích, góp phần xoá giảm đói nghèo. Cần tránh hai xu hướng thái quá trong QLTHVBB: theo kiểu cai quản, tuyệt đối hoá luật pháp và chế tài; hoặc theo kiểu "phong trào" với sự tham gia của cộng đồng chỉ là hình thức và vai trò quản lý Nhà nước bị xem nhẹ.

Từ nhận thức đến thực hành hiệu quả là cả một chặng đường khó khăn, cần đến ý chí chính trị của các cấp chính quyền từ Trung ương đến địa phương, cần một cơ sở lý luận vững chắc nhưng có sự áp dụng sáng tạo trong điều kiện thực tiễn Việt Nam.

\section{TÀI LIỆU THAM KHẢO}

1. Nguyễn Tác An (chủ biên), 2003. Hợp tác nghiên cứu xây dựng phương án quản lý tổng hợp đới ven bờ khu vực Nam Trung Bộ Việt Nam với điểm nghiên cứu trình diễn: vùng ven bờ biển tỉnh Bình Định. Báo cáo nhiệm vụ Nghị định thư Việt Nam Ân Độ. Lưu trữ tại Viện Hải dương học.

2. Chia Lin Cien, 1992. Singapore urban coastal area: Strategies for management. ICLARM Tech. Rep.31 99p.

3. Chua T.E. and others, 1996. Coastal environmental profile of the Batangas bay region. GEP/UNDP/IMO Regional Programme for the Prevention and Management of Marine Pollution in the East Asian Seas.

4. Chua T.E., 2001. An analysis of the aplication of integrated coastal management linking local and global environment concerns

5. www.coastman.net.co/publicaciones/mizc/ (0079).pdf

6. Clark, J.R., 1996. Coastal zone management handbook. Lewis Publishers, 694 ps.

7. Nguyễn Hũu Cử, 2005. Quản lý tổng hợp vùng bờ biển Việt Nam. Kỷ yếu Hội nghị 
Khoa học kỷ niệm 30 năm Viện Khoa học và Công nghệ Việt Nam, quyển III, trang $245-256$.

8. Dự án ICZM Việt Nam - Hà Lan. Delft Hydraunics Vietnam - Netherland integrated coastal zone management project. Project description. wwwldelft.nl

9. European Commission, 1999. Towards a European integrated coastal zone management (ICZM) strategy - General principles and policy options - EU demonstration programme on integrated management in coastal zones 1997 - 1999.

10. Hans Ackefors, Kjell Grip, 1995. The Swedish model for coastal zone management. Swedish Environmental Protection Agency. Priting Gotab. Stockholm. 83p.

11. Hendra Yusran Siry, 2006. Decentralized coastal zone management in Malaysia and Indonesia: A Comparative perspective. Coastal mangement, 34, 267 - 285. Taylor and \& Francis Group.LLC.

12. Nguyễn Chu Hồi, Nguyễn Hữu Cử, Lăng Văn Kẻn, 2000. Nghiên cứu xây dựng phương án QLTHVBB Việt Nam, góp phần đảm bảo an toàn môi trường và phát triển bền vững. Báo cáo tổng kết đề tài cấp Nhà nước KHCN.06-07 (1996-1999). Lưu tại Bộ Khoa học và Công nghệ.

13. Nguyễn Chu Hồi (chủ biên), 2005. Quy hoạch và lập kế hoạch quản lý tổng hợp vùng bờ vịnh Hạ Long, Quảng Ninh. Báo cáo tổng kết nhiệm vụ hợp tác Quốc tế Việt Nam - Hoa Kỳ theo Nghị định thư. Lưu tại Bộ Khoa học và Công nghệ.

14. Huming Yu and Nancy A. Bermas, 2009. Intergrated coastal management: PEMSEA'S practices and lessons learned. www2.unitar.org/hiroshima.

15. Nguyễn Thị Như Mai, 2007. Chính sách, pháp luật biển Việt Nam: thực trạng và giải pháp. Báo cáo thuộc nhiệm vụ: "Hoàn thiện và tổ chức thực hiện kế hoạch thực hiện chiến lược phát triển bền vững các biển Đông Á (Kế hoạch 2006)”, lưu trữ tại Cục Bảo vệ Môi trường. Hà Nội. 69 trang.

16. Maren Lau, 2005. Integrated coastal zone management in the People's Republic of China - An assessment of structural impacts on decision-making processes. No FNU-28, Working Papers from Research unit Sustainability and Global Change, Hamburg University. www.uni-hamburg.de/Wiss/FB/15/Sustainability.

17. Olsen S.B., Lowry K. and Tobey J., 1999. A manual for assessing progress in coastal management. Coastal management report. \#2211. The University of Rhode Island. Coastal Resources Center, Graduate School of Oceanography, Narragansett, RI 02882 USA. 61p. 
18. Nguyễn Ngọc Sinh, Hứa Chiến Thắng, Nguyễn Hữu Cử và nnk., 2003. Quản lý tổng hợp đới bờ - kinh nghiệm thực tế ở Việt Nam. NXB Lao động, Hà Nội.

19. Trần Đức Thạnh, 2007. Phát triển bền vững vùng biển Việt Nam, Hoạt động Khoa học. Số 574 , tr.13 - 14 và 18.

20. Trần Đức Thạnh, 2009. Những vấn đề ưu tiên đối với quản lý tổng hợp dải ven bờ tây vịnh Bắc bộ. Tạp chí Khoa học \& Công nghệ biển. 4(T.9), 127 - 146.

21. Hứa Chiến Thắng, 2007. Định hướng và kế hoạch xây dựng chiến lược phát triển bền vững biển Việt Nam. Báo cáo thuộc nhiệm vụ: "Hoàn thiện và tổ chức thực hiện kế hoạch thực hiện chiến lược phát triển bền vững các biển Đông Á (Kế hoạch 2006)", lưu trữ tại Cục Bảo vệ Môi trường. Hà Nội. 56 trang.

22. Thủ tướng Chính phủ, 2007. Quyết định số 158/2007/QĐ-TTg: Phê duyệt Chương trình quản lý tổng hợp dải ven biển vùng Bắc Trung bộ và Duyên hải Trung bộ đến năm 2010 và định hướng đến năm 2020.

23. UNEP, 1996. Guidelines for integrated planning and management of coastal and marine areas in the Wider Caribean Region, UNEP Caribean Environment programme, Kingston, Jamaica.

24. UNCED, 1992. Agenda 21, The Rio Declaration on Environment and Development. Rio de Janeiro, Brazil.

25. UNESCO, 1994. Excutive summary. International workshop on integrated coastal zone management (ICZM). IOC Workshop Report No.114: 66p. Karachi, Pakistan. 10 - 14 Oct.1994.

\title{
SOME PRINCIPAL ISSUES ON INTEGRATED COASTAL ZONE MANAGEMENT IN VIET NAM
}

\author{
TRAN DUC THANH
}

Summary: The integrated coastal zone management (ICZM) is the latest paradigm in concept of managing coastal areas, and approaching the balance on purposes of environment, society and economy in conformity with natural proccess. It is a state function with the manner of united and centralized management, and linked from central to local levels. Having the certain achievements, however, many efforts for ICZM have been still not sustainable yet that the most important reasons are concerned the lack of political will and weakness of just the centralized administrative management. 
Viet Nam has an institutional framework of advantage for ICZM which is being regarded as an indispensable orientation for sustainable development. Over ten last years, some research and demonstrative projects have contributed significantly to ICZM on the promotion of knowledge, enhancement of awareness, and accumulation of experiences by the international experts partly. Besides the initial results, the enterprise of ICZM is being faced to problems which need be solved such as basis of theory, legislational structure, capacities, methodology and sustainable financing etc. On the long path from awareness to good practices, ICZM needs the political commitment from central and local governments and creative application in the Vietnam practical context.

Ngày nhận bài: 02 - 3 - 2010

Ngườ nhận xét: PGS. TS. Nguyễn Chu Hồi 